\title{
Réplica a las críticas
}

Reply to critics

Francisco Saffie

Recepción: 27/10/20

Evaluación: 29/10/20

Aceptación final: 29/10/20

Resumen: Este texto responde a las críticas realizadas por Eleonora Lozano Rodríguez, Eurico Marcos Diniz de Santi y Hernán Bouvier al artículo "La racionalidad de los impuestos. Una tarea de reconciliación”.

Palabras claves: Derecho tributario, elusión, legitimidad, reconocimiento, solidaridad.

Abstract: This text addresses the critics made by Eleonora Lozano Rodríguez, Eurico Marcos Diniz de Santi and Hernán Bouvier to the article "The Rationality of Taxes. A Task of Reconciliation".

Keywords: Tax law, avoidance, legitimacy, recognition, solidarity.

\section{Introducción}

Parto por agradecer los comentarios recibidos por parte de la profesora Eleonora Lozano y los profesores Eurico Marcos Diniz de Santi y Hernán Bouvier. Me siento honrado de que hayan tenido el tiempo y dedicación para generar esta discusión. Agradezco además la paciencia que han tenido los editores y el equipo de Discusiones para sacar adelante este número en que

* PhD in Law, University of Edinburgh, Reino Unido. Profesor Asistente, Universidad Adolfo Ibáñez, Santiago de Chile. Post-Doctoral Global Fellow, New York University, Estados Unidos. Correo electrónico: francisco.saffie@uai.cl 
he demorado más de lo debido en preparar mi respuesta a las críticas. Quiero agradecer de manera especial el trabajo editorial de Alejandro Berrotarán.

A modo de disculpas por la demora, valga señalar que el esfuerzo por producir es mayor en estos tiempos en que la pandemia modificó la división del trabajo; la dedicación a tantas labores que habitualmente distribuimos entre muchos, hoy son asumidas individualmente (al menos en mi caso).

Esta respuesta tiene tres secciones, en cada una de ellas desarrollo por separado las respuestas a los comentarios de Eleonora, Eurico y Hernán. Preferí estructurar de esta manera la respuesta para tomar en serio las objeciones planteadas por cada uno de ellos. Una posible reconstrucción depurada de mi argumento, que se haga cargo de las posibles modificaciones que surjan como consecuencia de los comentarios de cada uno de ellos, tendrá que quedar para otra oportunidad.

Gracias nuevamente a todo el equipo de Discusiones.

\section{Respuesta a la profesora Lozano}

El comentario de la profesora Lozano se concentra en dos de los cinco puntos en los que resume el argumento de "La racionalidad de los impuestos. Una tarea de reconciliación” (en adelante, RDI). El primero punto de la crítica es sobre "el problema de la 'moralidad' tributaria"; el segundo, sobre lo que ella denomina "la construcción axiológica del derecho tributario". Contestaré ambos puntos en lo que sigue. Pero antes de comenzar, me gustaría hacer un comentario general, aplicable a todo el comentario de Lozano.

En términos generales, me parece que la diferencia esencial entre la crítica presentada por la profesora Lozano y el argumento que presenté en RDI está en que hablamos desde distintos lugares. Creo que Eleonora no considera que mi artículo intenta construir una fundamentación de la obligación de pagar impuestos y de su forma jurídica, distinta a la que se desarrolló por la comprensión política de la tradición liberal que ha dominado en materia de impuestos. En especial por la filosofía política liberal que sirve para justificar e interpretar las instituciones jurídicas del estado moderno. No descanso en esa comprensión por las limitaciones teóricas $y$ normativas que representa para explicar la forma en que la modernidad 
supone espacios para el desarrollo de la dimensión individual y la dimensión colectiva de la vida. El punto de mi artículo es que esa incapacidad para dar cuenta de esos dos espacios que son propios de la interacción social moderna, deben ser incorporados institucionalmente para resolver, en materia tributaria, una cuestión tan relevante como la elusión. En este sentido, al menos desde el título de mi artículo principal, intento desarrollar lo que podría denominarse una concepción hegeliana de la obligación legal de contribuir para reconciliar al individuo con la dimensión social de los tributos (en general -y de los impuestos en particular-) como dimensiones de lo individual y lo colectivo que permiten el desarrollo ético de las personas ${ }^{1}$. En este sentido, y basta leer el título del artículo principal, mi propuesta está muy influenciada por la lectura que Michael Hardimon hizo de la filosofía social de Hegel (Hardimon, 1992 y 1994).

Porque es posible que la exposición de mis argumentos en RDI haya sido poco clara o que haya dado por sentado algunos elementos del trasfondo de las ideas que quiero expresar, parte de mi respuesta a la profesora Lozano consistirá en desarrollar con más claridad mi objetivo y, además, dar cuenta de la teoría del derecho que utilizo para desarrollar la concepción de los impuestos que presenté en el trabajo principal. La conclusión de mi respuesta a Eleonora es que la reconstrucción que hace de mi argumento yerra en el contenido de lo que ella describe como "etapas" de mi argumento.

\section{1. ¿A qué me refiero con "ética” y qué rol juega el "recono- cimiento recíproco como parte del comportamiento ético"?}

La primera cuestión, entonces, supone clarificar qué entiendo por "comportamiento ético" y para eso es bueno diferenciar el trasfondo que explica las diferencias en el uso de los conceptos entre la profesora Lozano y yo.

Eleonora entiende por ética la ciencia que estudia el lenguaje moral y que mediante distintas teorías revisa las pretensiones de validez de los

1 De los hombres dije en el texto principal, queriendo hacer referencia a las personas, sin afán de realzar el patriarcado negando las demandas de justicia feministas. 
enunciados morales. Es la forma estándar, por decirlo así, de la ética. Por ello le parece extraño mi uso del concepto "ética". Esas diferencias llevan a Lozano a sugerir que el uso correcto de estas categorías supone que mi argumento se refiere a "la moral de los ciudadanos libres más que a la ética". De esta manera, para la profesora Lozano, que en esto sigue a Tipke, la ética tributaria debería "corresponder al estudio de la moralidad en materia tributaria según el desarrollo de los principales sujetos involucrados en la operación del sistema tributario". En otras palabras, para Lozano, mi argumento debería enmarcarse en lo que tradicionalmente se llama "ética tributaria" o, en el mundo anglosajón, "tax morale". Esta forma de abordar el derecho tributario supone revisar la forma en que la moral, entendida como el correcto actuar individual, influye en el nivel de cumplimiento tributario de los contribuyentes.

Nadie dudaría que el estudio de la "ética tributaria" es relevante. En este sentido, el estudio de las razones que llevan a las personas y las empresas a pagar sus impuestos permite el diseño de políticas tributarias más efectivas para aumentar los niveles de recaudación. Véase, por ejemplo, además del análisis desarrollado por Eleonora en su comentario, el reciente estudio de la OCDE (2019), "Tax morale: what drives people and businesses to pay tax?". De hecho, superado lo que Lozano denomina "problemáticas conceptuales" por las que sugiere que en el lugar de "ético" debería yo hablar de "moral", sostiene que el tema de discusión en esta parte podría entenderse conforme a si "la 'moral' incluye o no en el nivel de cumplimiento tributario de los contribuyentes". Para ello hace referencia a un trabajo del que ella y Tamayo son autores, en que concluyen: "son varias las variables que influyen en el comportamiento de las personas en lo que respecta a sus responsabilidades tributarias, que podrían dividirse en dos grupos".

Asumo para efectos de esta respuesta que la razón por la que Eleonora vincula los trabajos de "ética tributaria" con mi trabajo, descansa en la manera en que planteo la discusión del cumplimiento de las obligaciones tributarias y la elusión. El problema es que el punto que quiero hacer en mi trabajo es distinto. Mi interés en realizar una reconstrucción de los fundamentos del derecho tributario, como parte de una tarea de reconciliación, no dice relación con las razones que cada contribuyente tiene o podría tener para el cumplimiento de sus obligaciones tributarias, sino con ofrecer 
una posible justificación para la existencia de un deber jurídico de pagar impuestos. Con esto quiero decir, justificar los impuestos: i.e., justificar que exista un deber jurídico (con el contenido substantivo propio de las obligaciones tributarias) con determinadas características (con la estructura característica de las obligaciones tributarias) que se impone a los contribuyentes con independencia de si adhieren internamente a esa institución.

En otras palabras, lo que me interesa es justificar por qué existen los impuestos, qué es aquello a que dan forma las instituciones jurídicas del derecho tributario y qué consecuencias tiene esa justificación y forma jurídica para la aplicación del derecho tributario a un caso particular. Y la justificación que doy, por las razones si se quiere "hegelianas" sobre las que se construye, no puede ser -a mi juicio- puramente instrumental (esto es, el financiamiento del gasto público).

Espero que esta breve explicación muestre por qué pienso que una justificación de la institución, como la que propongo en el artículo principal, no requiere de la adhesión interna de los contribuyentes. Tal como explicó H.L.A. Hart (1994) cuando se refirió a las condiciones necesarias para la existencia de un sistema jurídico: el punto de vista interno es condición necesaria cuando se refiere a los funcionarios del sistema encargados de exigir el cumplimiento de las normas primarias de conducta. No es necesario exigir que el ciudadano, en este caso, una o un contribuyente, cumpla con sus deberes tributarios por adherir a las razones que dieron origen a la ley, basta que tenga cualquier razón para hacerlo (incluido el temor a recibir una sanción). Tampoco es necesario, para la tarea filosófica que me pongo por delante, conocer las razones que las y los contribuyentes podrían tener para cumplir con sus obligaciones.

Lo que sí me interesa argumentar en RDI, es que una justificación no instrumental de las obligaciones del derecho tributario y, por tanto, de una manera alternativa a las justificaciones liberales, es siendo parte de la "ética" o Sittlichkeit. El punto, entonces, es justificar que las obligaciones tributarias son del tipo de obligaciones que nos debemos unos a otros, no solo por lo que podemos hacer con esos recursos, sino porque nos definen recíprocamente como individuos (mediante el reconocimiento recíproco). ${ }^{2}$

2 Quizá otro autor que sirva para esta diferenciación entre ética y moral es Habermas. 
En otras palabras, esta justificación busca reconciliar al individuo con las obligaciones colectivas que le son impuestas por ser parte del Estado moderno. La idea es mostrar cómo "la familia, la sociedad civil, y el estado forman un solo sistema inteligible y coherente que promueve tanto la individualidad como la comunidad" (Hardimon, 1992, pp. 165-195). Se trata de un proyecto filosófico porque busca "reconciliar a las personas [con las condiciones de vida del mundo moderno] proveyéndoles una comprensión filosófica de las instituciones sociales centrales que les permitirán ver a pesar de las apariencias. El proyecto intenta reconciliar proveyendo una mejor comprensión racional (verniinftige Einsicht) a la verdadera naturaleza del mundo social" (Hardimon, 1992, p. 171-172).

La cuestión entonces es que las personas logren conectarse con el mundo social desde la dimensión cognitiva "si en principio pueden entender la organización, operación y principios subyacentes de sus instituciones centrales". La idea es que las personas "deben entender (begreifen) sus arreglos institucionales básicos, y en consecuencia para poder estar en casa, el mundo social debe permitir ser comprendido" (Hardimon, 1992, p. 187) ${ }^{3}$.

Aquí Eleonora podría objetar que parte de esa explicación pueden ser lo que yo descarto por pertenecer a "tax morale". ¿Cómo justificar la diferencia entre estos tipos de razones?

Nótese que la tarea de Hegel o la interpretación de su proyecto supone encontrar razones para que las personas entiendan los arreglos institucionales en los que viven. Esto tiene similitudes con el resto de la filosofía política, pero no es lo mismo que pensar en cómo diseñar reglas según la voluntad de los contribuyentes para cumplir con esas obligaciones. De esta manera, decir que "el mundo social es un hogar, no es equivalente a decir que satisface todas y cada uno de nuestros deseos. Es, de manera más precisa, decir que no hay una dimensión objetiva relevante de la que estemos separados. Lo que está en cuestión aquí es la alienación, no la felicidad" (Hardimon, 1992, p. 187). En otros términos, se trata de reconciliar obligaciones impuestas por el Estado para ser explicadas como autónomas.

3 Estas líneas también pueden servir para adelantar algunas de las objeciones de Hernán Bouvier a RDI. 
En el esquema Hegeliano en el que trato de enmarcar mi explicación de los tributos, lo que es importante es garantizar la libertad. Es eso lo que supone el desarrollo ético de las personas, esto es la vida ética.

El problema de la elusión aparece así no como uno respecto de las razones (morales, en el lenguaje de Eleonora) que tienen los contribuyentes para cumplir con sus obligaciones, sino en cómo, a nivel del Sittlichkeit, las obligaciones tributarias son parte necesaria de la libertad individual.

La crítica que alguien podría esbozar a este proyecto entonces es que corre el riesgo de ser ideológica, en el sentido de Marx, esto es, de adolecer de falsa conciencia. Quizá a esto es a lo que se refiere la crítica de Hernán Bouvier a mi trabajo. Volveré sobre esto al responder el comentario del profesor Bouvier.

\section{2. ¿Cómo la relación entre tributación y derecho de propiedad posibilita la construcción del derecho tributario sobre principios?}

En este caso intencionalmente hago una modificación a la forma en que Eleonora plantea su crítica. Lo que elimino del título es la equivalencia que hace la profesora Lozano a una construcción de un área del derecho basada en principios y su asimilación, por esa razón, a una concepción del derecho distinta al derecho positivo. En sus términos "posible construcción del derecho tributario sobre principios y no sobre derecho positivo" (destacado agregado).

No hay razón alguna para sostener que la distinción entre principios y reglas es una distinción entre el derecho positivo y otras concepciones del derecho. Quizá la forma más adecuada de especificar esta cuestión es que la distinción entre reglas y principios no es una necesariamente equivalente a la distinción entre derecho y moral, o necesariamente con la discusión entre el positivismo excluyente y el positivismo incluyente. Es perfectamente posible utilizar estas categorías para dar cuenta de distintas concepciones de los enunciados normativos: algunos adoptan la forma de una regla $y$ otros pueden tener una forma de principios. Al menos esta es la interpretación que hago del trabajo de Judith Freedman. Vale decir, no como un 
recurso a la moral (como lo haría una concepción positivista incluyente) ni como una referencia a la aplicación de la constitución (como podría ser una concepción principialista de la constitución -o neoconstitucionalistaidentificada con, y derivada de, las ideas de Alexy).

Eleonora reconoce en su respuesta que existen otros tipos de concepciones de los principios jurídicos. Quizá debí ser más explícito para mostrar cómo una concepción como la defendida en mi texto podría dar espacio para una reconstrucción de la forma del derecho tributario que haga posible la realización adecuada de su justificación.

En este sentido, los principios jurídicos pueden ser entendidos en la forma en que lo hace Raz o Marmor. Esto es, como parte del derecho positivo pero como normas que confieren potestades interpretativas a los órganos judiciales o administrativos. Se trataría de delegación de facultades por parte del legislador.

Ahora bien, creo haber sido claro en RDI que no apoyo la idea de reconstruir el derecho tributario sobre principios, incluso bajo una comprensión positivista. Esa es la apuesta que hace Judith Freedman. A mi juicio de manera errada porque desconoce la importancia de la forma jurídica (cuestión a la que vuelvo al final de mi respuesta al trabajo de Hernán Bouvier). De hecho, la propia profesora Lozano reconoce esto cuando señala: "Saffie critica esta solución por entender que el análisis del derecho tributario sobre una cuestión principiológica lo convierte en una categoría vacía, ya que no tendrá un contenido sustantivo (a pesar de prometer uno), además de poner en peligro la idea de legislación y aplicación, causando dos consecuencias: mantenimiento de la falta de legitimidad y falta de comprensión entre la forma y la sustancia; no hay un derecho tributario que pueda ser aplicado al caso particular, a no ser por medio de una legislación específica”.

\section{Respuesta al profesor Eurico Marcos Diniz de Santi}

En "El papel de la solidaridad en el fundamento del Derecho Tributario: análisis de la solución de reconciliación propuesta por Francisco Saffie en la racionalidad de los impuestos y la idea de reciprocidad frente a la noción 
de ciudadanía fiscal", el profesor Eurico Marcos Diniz de Santi, analiza en extenso mi argumento para argumentar que la solidaridad es necesaria pero no suficiente para resolver los problemas actuales del derecho tributario. Eurico ofrece una alternativa paralela a la que expongo en el artículo principal para mostrar cómo podrían superarse los problemas del derecho tributario en un sistema como el brasilero. A mi juicio, sin embargo, el profesor Santi va demasiado rápido. Si bien mi argumento podría encuadrarse en las categorías tradicionales y ser complementado para justificar que la solidaridad no basta, hay ciertas consecuencias y problemas que mediante ese encuadre no logran resolverse.

Partamos por los puntos en que podemos estar de acuerdo. No hay duda que un sistema complejo y opaco puede generar problemas de legitimidad y de cumplimiento (el sistema tributario brasileño es reconocido en el mundo por su complejidad y, como nos informa Eurico, por su opacidad).

En lo que parecemos no estar de acuerdo es en qué supone la legitimidad y cuáles son las consecuencias que tiene para el cumplimiento. En este punto el profesor Santi, al igual que la profesora Lozano en su comentario, está preocupado de cómo alcanzar el "enforcement para la legitimidad y el pago del tributo" aún "si tomáramos la premisa de que el paradigma clásico [...] se muestra equivocado y que la propiedad y la tributación son dos caras de la misma moneda", como argumenté en RDI.

A juicio de Eurico, la falta de legitimidad de un sistema tributario puede deberse a otras razones distintas de la justificación de los tributos. En ese listado enumera: la determinación de la carga tributaria, la existencia de opciones lícitas para disminuir la carga tributaria, el modo de recaudación, falta de legitimidad por una carga tributaria excesiva, etc.

El problema de esta perspectiva, de nuevo, es que no se toma en serio el plano de discusión al que me interesa llegar. No se trata simplemente de determinar que la comprensión del ciudadano se necesita para que este entienda que debe pagar impuestos para vivir en comunidad, su carácter redistributivo o que se requieren para financiar el gasto público, como Eurico parece creer que se concentra mi trabajo. Mi punto es distinto. Es un punto filosófico que busca superar la alienación, que en el derecho tributario, se observa en las limitaciones de una justificación que da por sentado el rol de los impuestos frente a la propiedad privada. En otros términos, 
es más similar a la tarea que desarrollan Murphy y Nagel en The Myth of Ownership. Parafraseando el análisis desarrollado por estos autores, la respuesta de Eurico a mi trabajo no considera el problema del libertarismo cotidiano: está pensando que el problema de la legitimidad se da porque existe algo así como una distribución de mercado que es afectada por los impuestos y cuya justificación requiere desarrollo, como si alguien pudiese ser titular de propiedad privada antes de impuestos (por eso el tipo de preguntas de "legitimidad" que se plantea Eurico).

Lo anterior no es lo mismo a asumir, como hacen varias constituciones, y nos recuerda Santi sobre la Constitución brasileña, que la propiedad no es un derecho absoluto. $\mathrm{O}$ al menos no basta con eso. El punto es precisamente que esa relación entre propiedad e impuestos en la cual son conceptos recíprocamente dependientes requiere de una forma jurídica que le dé cuerpo. Establecer a nivel constitucional la función social de la propiedad no es suficiente si la forma jurídica en que nacen las obligaciones tributarias supone hacer prevalecer el derecho de propiedad privada, como ocurre con la relación jurídica tributaria bajo el paradigma clásico. Mi punto es que la relación propiedad/solidaridad de que da cuenta el profesor Santi no es constitutiva, sino que requiere resolverse mediante ponderación. En cambio, la relación por la que argumento en mi trabajo no es la "tradicional" forma de resolver el conflicto entre propiedad e impuestos mediante las características propias del Estado Democrático y Social de Derecho, sino que ambas dimensiones son expresiones del mismo derecho a la autonomía (la privada y la pública) en distintos niveles (siguiendo el esquema de Hegel).

Mi argumento supone reconfigurar la relación entre propiedad e impuestos de forma tal que no se puede dar lugar, al explicar la obligación de pagar impuestos a una lucha de "vectores". Es la idea que el profesor Santi tiene al no salir del "paradigma clásico", esto explica una afirmación como esta: "El sistema tributario es hipercomplejo, diversos y sucesivos escándalos de corrupción, errores de gestión de los asuntos públicos y falta de prestación de servicios públicos básicos que el Estado se propone desarrollar, como salud, educación y seguridad, los cuales también tienen una perspectiva redistributiva, impulsan la disminución del vector de la solidaridad, así considerada la transferencia de riqueza al Estado, y causan un 
aumento del vector de preservación de la propiedad privada" (Gonçalves, 2002, p. 175).

Esta diferencia de aproximación, a mi juicio, permite además mejorar desde una perspectiva analítica, los problemas a los que hacemos referencia cuando buscamos controlar o hacer más eficiente el gasto público. Si la justificación para la obligación de contribuir es distinta de la justificación del uso de los recursos públicos, aparece de inmediato la diferencia que realizan las instituciones a cargo de uno y otro asunto. Así, por un lado, los tributos están a cargo de determinar la forma en que cada contribuyente satisface su obligación ciudadana; mientras que por otra parte, una institución distinta, esto es, la ley de presupuestos, se encarga de determinar la forma y requisitos sobre los recursos que se destinan a financiar los gastos públicos. La diferencia institucional es relevante y aunque aquí no tengo espacio para desarrollar el detalle, es importante notar que la ley de presupuesto es una forma de decidir sobre bienes colectivos por medio de los representantes, no se trata de la identidad de lo que se hace con mi dinero siendo yo quien tiene potestad para determinar su uso, como pretenden ciertas ideas sobre los impuestos derivadas de lo que denomino el paradigma clásico.

Todo lo anterior no implica que al evaluar instituciones no se recurra a argumentos de eficiencia. En ese sentido, si la administración de recursos por parte del Estado, como argumenta Eurico, es de "clara ineficiencia, con una gradual alteración de funciones y recursos públicos para los entes privados, como organizaciones no gubernamentales", es evidente que se requiere revisar el desempeño de la administración. Pero el profesor Santi estará de acuerdo conmigo, espero, en que el suyo es un argumento distinto al que me interesa desarrollar a nivel filosófico sobre la justificación de la obligación de pagar impuestos no por el uso instrumental que se haga de esos recursos. De hecho, mi argumento busca mostrar que la obligación de pagar impuestos es completamente independiente del uso que se haga de los recursos fiscales. En otras palabras, en mi argumento, la obligación de pagar impuestos no está condicionada por su uso: ya sea para fines redistributivo o por su uso eficiente para el financiamiento de bienes públicos. Insisto, eso no quiere decir que no sea relevante lo que se hace con esos recursos, pero existen instituciones distintas de los impuestos para lidiar con ese asunto. 
Entiendo que las diferencias anteriores son las que llevan al profesor Santi a ofrecer una relación entre solidaridad y propiedad "paralela" a la que desarrollo en mi trabajo y, por lo mismo, no busca "refutar [mis] argumentos sino [presentar] otros puntos de vista". Sin embargo, me parece que esas son palabras de buena crianza por parte del profesor Santi porque al proponer que "los problemas de legitimidad y cumplimiento de las obligaciones tributarias más allá de la idea de solidaridad" se pueden resolver con "características concretas del sistema tributario observadas en la sociedad" como son la "simplicidad y la transparencia" asume que existe una relación propietaria del contribuyente respecto del gasto público que es propia del paradigma clásico.

En definitiva, la idea de "ciudadanía fiscal" entendida como "el empoderamiento del ciudadano frente al sistema tributario, permitiéndole comprender qué, cómo, cuánto, cuándo y dónde se adeudan los impuestos, influyendo o no en su institución y, por otro lado, pudiendo, también, posicionarse contra medidas ilegales en el intento de recaudar los impuestos y exigir medidas sensibles frente a los demás particulares y en relación con los servidores públicos" es una definición cuyo contenido es indefinido.

El último punto al que me quiero referir en respuesta al profesor Santi es sobre la relación entre solidaridad y reconocimiento recíproco. En una movida que llama la atención, Santi sostiene que debemos abandonar la idea de solidaridad por asociarse a "una postura pasiva. De dependencia mutua que se establece entre dos o más personas". La solidaridad, como la entiende Santi, es “unilateral y estática, no exige una acción”. A su juicio, la solidaridad debería reemplazarse por reciprocidad. Según Santi, a diferencia de la solidaridad la reciprocidad "implica dar y recibir, una situación de compromiso con el todo. No es suficiente solo sentir, sino también tener una iniciativa de participación. En este sentido, tenemos la idea de compartir. Implica dar, recibir y nutrir el sistema en su conjunto, construyendo una relación de responsabilidad y representatividad del individuo con el colectivo. La reciprocidad es bilateral y dinámica, requiere compromiso".

Creo que la definición de solidaridad adoptada por el profesor Santi, confunde solidaridad con caridad. La caridad, a diferencia de la solidaridad, supone una posición desigual en la cual quien actúa caritativamente desconoce la igualdad del otro. Por el contrario, la solidaridad podría 
"implicar un cierto tipo de apoyo activo de la búsqueda de felicidad de otro, de manera tal que uno de cierta forma comparte la definición de lo bueno del otro" (Rehg, 1997, p. 107). Es más, para Habermas, por ejemplo, la solidaridad esta "enraizada en que cada persona debe hacerse responsable de la realización del otro porque como coasociados, todos deben tener el mismo interés en la integridad del contexto de vida compartido" (Habermas, 1990, p. 244).

La solidaridad de la que darían cuenta los impuestos, según la justificación propuesta en mi texto, es parte del desarrollo ético de los individuos en el nivel del Estado, como última etapa del reconocimiento recíproco que nos debemos en la dimensión o rol de ciudadanos. Vale decir, la solidaridad como fundamento de los impuestos es un concepto político o si se quiere (volviendo a la discusión con Eleonora Lozano) ético.

Aquí es necesario hacer una pausa en el argumento, para retomarlo en mi respuesta al profesor Bouvier. Ahí abordaré con algo más de detalle la relación y las diferencias entre reciprocidad y reconocimiento recíproco (y las consecuencias que tiene para la vida ética y la noción de solidaridad), a propósito de la discusión que el profesor Bouvier presenta sobre mi interpretación del trabajo de Rawls.

Para finalizar mi respuesta al profesor Santi me gustaría terminar por aclarar que la diferencia entre su posición y la mía radica en la forma en que el individuo se entiende a sí mismo como parte del todo. El profesor Santi defiende la idea de "ciudadano fiscal" que en realidad es la idea del individuo que se informa y exige un gasto eficiente de lo que ella pagó coactivamente al Estado; en mi caso, la idea de ciudadanía supone una comprensión de un rol en que el individuo es igual a otros y para ser reconocido por los demás como un igual, satisface ciertas obligaciones colectivas, una de las cuales es el solucionar sus impuestos.

\section{Respuesta al profesor Hernán Bouvier}

El profesor Bouvier plantea problemas distintos a los presentados por la profesora Lozano y el profesor Santi porque no intenta volver a encuadrar mi argumento en la tradición liberal-kantiana. La crítica de Bouvier es 
elegante, creativa y difícil de responder porque hace el esfuerzo de aceptar los presupuestos filosófico-políticos de mi trabajo para realizar un cuestionamiento de la forma en que sostengo mi argumento y de la aplicación del modelo alternativo al paradigma clásico que busco construir. Quizá, si lo entiendo bien, en algunos pasajes de su crítica Bouvier plantea que la tradición liberal-kantiana, al menos en alguna lectura de Rawls, podría acomodar mi reconstrucción e incluso dar cuenta mejor de los impuestos que la reconstrucción que intento en RDI. En lo que sigue intentaré contestar punto por punto la crítica de Bouvier.

\subsection{Explicar, dar cuenta y justificar}

La primera crítica de Bouvier se refiere al tipo de problema que busco identificar en el paradigma clásico del derecho tributario. Tiene razón Bouvier en que el paradigma clásico puede ser entendido como una "explicación". De hecho, podría entenderse como una explicación empírica, teórica y además, una justificación normativa de los impuestos. ${ }^{4}$ Por lo mismo es que mi intención al ofrecer el paradigma clásico fue reconstruir de la mejor forma posible la explicación que podría ofrecerse hoy de los impuestos. ${ }^{5}$ En todos los sentidos que Bouvier distingue y le interesan mostrar -al menos en su crítica-, es cierto que el paradigma clásico rinde: es una explicación empírica-social, también es una explicación teórica (ya sea como análisis de sus partes integrantes para proveer claridad conceptual; en un sentido relacional para diferenciarlo con otros conceptos con los que aparece

4 No intentaré en esta respuesta plantear una discusión sobre estas categorías. Asumiré para todos los efectos que siguiendo estas distinciones en la forma planteada por Bouvier puedo contestar sus objeciones clarificando el propósito de mi crítica al paradigma clásico. En otras palabras, no discutiré si el derecho es el tipo de cosa que se deja explicar científicamente o si es de aquellas que deben ser entendidas. Véase: (Moon, 1977, pp. 183-198; Ruben, 1990, pp. 75-117; Skorupski, 1990, pp. 119-164 y Taylor, 1970).

5 Por lo mismo, diría que es una virtud de mi argumento haber reconstruido de esa forma el paradigma clásico. El punto es que esa reconstrucción no puede explicar de la mejor forma por qué tenemos una estructura legal como la que tenemos para los impuestos. En este mismo sentido, es posible explicar que los impuestos sirven para financiar el gasto público. Esa es una explicación funcional que puede servir para determinados contextos. Pero esa explicación 
habitualmente asociado; $y$, al encontrar un mínimo común denominador entendido como la propiedad básica de todos los conceptos analizados), y además, tiene una justificación normativa. Entiendo que todo lo anterior no implica que sean buenas explicaciones, ni que no pueda criticarse el paradigma clásico. La cuestión es que Bouvier considera que RDI no es explicación suficiente en ninguno de estos sentidos.

Primero, parto por aceptar que en RDI no desarrollo el argumento siguiendo este esquema o estas distinciones respecto de cómo se puede explicar el derecho tributario. De hecho, una razón por la que no lo hago es porque no creo que todos estos sentidos de explicación sean relevantes para lo que busco hacer en RDI. En primer lugar, es claro, que RDI no pretende ser una explicación empírico-social. Tampoco podría serlo. Es más, una explicación empírica-social en estos términos me parece que haría imposible la idea que anima al proyecto de RDI: plantearse críticamente frente a la comprensión actual del derecho tributario.

En cuanto a la dimensión teórica, el problema de la crítica de Bouvier consiste en asumir que una explicación funcional puede ser adecuada para responder ¿qué es el impuesto? Dice Bouvier "sostener que [el impuesto] es aquello que se paga como contraprestación para sostener los gastos colectivos y estatales que van en su propio interés", explica "muy bien qué son y para qué están los impuestos bajo una cierta ideología”. Claro, esta explicación muestra "para que están" los impuestos conforme a una "cierta ideología”. Si entiendo bien el punto de Bouvier, cualquier explicación que muestre las consecuencias que se siguen de una generalización normativa, bastaría como explicación. Eso lleva a Bouvier a sostener que RDI es, al final de cuentas, una alternativa que todavía debe mostrar qué explica mejor teóricamente y por qué es una mejor justificación que el paradigma clásico.

Para responder estas críticas de Bouvier me quiero concentrar en la incapacidad del paradigma clásico para mostrar por qué la elusión tributaria es un problema legal. No tengo aquí todo el espacio que necesito 
para desarrollar este punto, pero espero al menos mostrar sus elementos centrales.

El paradigma clásico entiende la elusión tributaria como un comportamiento legal que deja sin aplicación el derecho tributario. Todos los elementos que son parte de la explicación teórica del paradigma clásico muestran que la obligación tributaria es, al final de cuentas, una relación jurídica cuyo surgimiento dependerá de la concreción del hecho generador de la obligación. En la llamada teoría del hecho imponible, la verificación del presupuesto de hecho de la norma jurídica tributaria determina el surgimiento de la obligación de la contribuyente. RDI, entonces, busca mostrar que de ser correcta la comprensión de la elusión tributaria que se construye a partir de la relación jurídica de derecho tributario -que descansa en el paradigma clásico-, se vuelve incoherente un principio básico de esta área del derecho: que las obligaciones tributarias tienen su origen en la ley y no en la voluntad de las partes o en la voluntad de la administración. De esta manera, mostrando el defecto del paradigma clásico para conceptualizar la elusión tributaria, la explicación teórica del paradigma clásico privatiza la obligación de derecho tributario.

Claro, Bouvier podrá insistir en que no ve lo malo de esa explicación porque todavía queda por justificar normativamente que el derecho tributario no debería privatizarse. Que no es necesaria una concepción pública del derecho tributario si lo que atendemos es a la "función" de los impuestos, esto es, a su uso. Lo relevante en este caso sería que se cumpla esa función. El problema con esa explicación funcional es que no avanza en responder la pregunta ¿Por qué? ¿Por qué los impuestos y no otros mecanismos para financiar el gasto público? ¿Qué es el impuesto más allá del uso de los recursos que se obtienen coactivamente?

El punto entonces es que la respuesta a ¿Por qué se debe tributar? no nos sirve para explicar los impuestos. La pregunta es ¿Por qué se tributa mediante impuestos? La respuesta a esta pregunta nos lleva a la cuestión de la justificación.

Según Bouvier RDI “supone un modelo alternativo [...] pero no indica con éxito por qué es superior normativamente”. Volveré sobre este punto más adelante. 


\subsection{Los integrantes del paradigma clásico y la noción de impuestos como instrumentos}

La discusión planteada por Bouvier pone en duda mi inclusión de las concepciones de los impuestos defendidas por Rawls y por Holmes y Sunstein en el paradigma clásico.

En el caso de Rawls, la pregunta es "en qué sentido [...] puede ser incluido sin más en una concepción meramente instrumental de los impuestos, basada simplemente en las características $i$-iii del paradigma clásico". Mi respuesta podría partir por hacer una diferencia entre el Rawls de la Teoría de la Justicia y el "tardío" de la Justicia como Imparcialidad. En el caso de la Teoría de la Justicia, los presupuestos de las tareas asignadas a los impuestos son principalmente redistributivas o para financiar el gasto público. ${ }^{6}$ En ambos casos, la explicación de Rawls satisface las características i-iii del paradigma clásico. No siendo eso suficiente para Bouvier como explicación, agrego que plantear la discusión sobre los impuestos justificados en fines redistributivos, muestra que lo relevante para Rawls (en la Teoría de la Justicia) es justificar la redistribución como razones morales para aceptar la afectación de la propiedad. El punto de RDI es que impuestos y propiedad se definen recíprocamente. No podemos asumir, por las razones presentadas por Murphy y Nagel en The Myth of Ownership, que existe tal cosa como propiedad antes de impuestos. Si uno sigue hasta sus últimas consecuencias la idea que los impuestos definen institucionalmente la propiedad (y que esta es un concepto institucional y no natural), no se necesita justificar la redistribución porque esta siempre fue parte de las condiciones de la propiedad.

Podría argumentarse, siguiendo a Bouvier, que el Rawls tardío contesta mi objeción al poner "énfasis en la reciprocidad, la cooperación mutua, el sentido de justicia”, lo que lo excluiría del paradigma clásico para dejarlo como un tercero no excluido entre ese paradigma y RDI. En este caso, Bouvier me pide "conocer en qué sentido la idea de Rawls de reciprocidad es lejana u opuesta a la idea de solidaridad y fraternidad". Aquí mi respuesta a Bouvier conecta y continúa con lo que antes con-

6 Para más detalles véase: Saffie, 2012, pp. 123-161. 
testé a Santi sobre la solidaridad. El argumento de Bouvier es similar al desarrollado por Thom Brooks en "Reciprocity as mutual recognition" (Brooks, 2012, pp. 21-35). El punto es el siguiente: la reciprocidad tiene un rol fundamental en la forma en que un sistema democrático de propietarios (property owning democracy) y de socialismo liberal (liberal socialism) son regímenes mejor equipados para satisfacer los dos principios de la justicia por sobre otros, como el capitalismo del laissez-faire, el capitalismo del estado de bienestar y el socialismo estatal. En los dos primeros regímenes la reciprocidad se lograría mejor que en los otros. Brooks por ejemplo llega tan lejos como a sostener que "a mi parecer Rawls entiende que la reciprocidad incluye algo más, que se trata de una forma de reconocimiento recíproco y de identidad compartida" (Brooks, 2012, p. 27). De esta manera, a juicio de Brooks, Rawls no estaría tan lejos de Hegel como lo planteo en RDI. Es más, el argumento de Brooks es que la concepción de reciprocidad Rawlsiana debe ser entendida como "reconocimiento recíproco para dar cuenta de mejor forma de su naturaleza que supone involucrarse activamente con otros. Este involucramiento es central para la formación de una identidad política compartida. Esta identidad compartida incluye un sentido de confianza, reconocimiento, y respeto entre iguales. Es la importancia de ser reconocido y tener un sentido de reconciliación con la sociedad política lo que es central" (Brooks, 2012, p. 32). El problema de esta lectura de Brooks es que Rawls parece que deja de ser Rawls y pasa a tener una concepción mucho más robusta del bien que lo aleja de la comprensión liberal de la comunidad política. De hecho, Brooks afirma "El argumento de Rawls para la igualdad democrática debería incluir la idea que la legitimación liberal es la reconciliación política en donde nos reconocemos unos a otros como ciudadanos iguales que pertenecen juntos a una comunidad política con una identidad compartida". En otras palabras, asumir que reciprocidad es equivalente a solidaridad. Pero esto es equivalente a sostener que existe identidad entre la legitimidad liberal de una comunidad política y el Sittlichkeit Hegeliano. Si es así, creo que podría aceptar que Rawls no es parte del paradigma clásico, pero dudo que un liberal Rawlsiano esté dispuesto a asumir esta posición que implica renunciar al liberalismo político. 
La razón para clasificar el argumento de Holmes y Sunstein en El Costo de los Derechos: por qué la libertad depende de los impuestos es que se trata de una justificación que atiende exclusivamente al uso de los recursos que se obtienen mediante impuestos como razón suficiente para mostrar la necesidad de tener impuestos. Se trata, nuevamente, de un argumento que muestra cómo se da por hecho el paradigma clásico. El punto aquí es mostrar porque se trata de recursos que se necesitan para asegurar derechos. Para la justificación que presento en RDI, al concentrarse en los impuestos y no sus usos, estas razones no dicen relación con los impuestos sino con el uso de los recursos fiscales.

\section{3. Prácticas, bien interno e instituciones}

Bouvier sostiene que "no es claro cuál sería la práctica no institucional que tiene un valor que hay que seguir" cuando me refiero a la práctica preinstitucional sobre la que se institucionalizan los impuestos. Efectivamente, como señala Bouvier, se trata de determinar "algo que puede existir sin impuesto, y que los impuestos realizan”, esa práctica debería tener de alguna forma elementos de reconocimiento y solidaridad en términos genéricos. Quizá de una forma poco convincente ( ¿se necesitan datos empíricos para tener más fuerza?) lo que sostengo es que la práctica preinstitucional es la dimensión puramente económica de los impuestos. Si se quiere, lo que siempre ha existido es la necesidad de contar con recursos comunes para algún fin común. Esa es la práctica: costear necesidades comunes. La institucionalización de esa práctica, la forma en que se desarrolla y se definen las posiciones, privilegios y derechos ${ }^{7}$, son los impuestos. En la práctica, a diferencia de la institución, no hay reglas.

El problema, según entiendo de las objeciones de Bouvier, es que para él la práctica y la institución son equivalentes. No estoy seguro que esa equivalencia logre mostrar adecuadamente la relación entre una práctica y su institucionalización. El problema es asumir que la práctica institucional es equivalente a la práctica preinstitucional. En el caso del derecho, la

7 Parafraseando la definición de institución usada por Rawls en "Dos conceptos de reglas". 
pregunta que quedaría abierta es para qué tenerlo si todos cumpliríamos de manera voluntaria; todos quienes participan en la práctica preinstitucional parecerían estar de acuerdo en que el bien justificaría el comportamiento. Eso es lo que Bouvier niega cuando dice: si participa y niega, en realidad no participa; si participa, excluye la posibilidad de objetar esos supuestos bienes. Pero la cuestión es un poco distinta. Yo diría, siguiendo a MacIntyre que es más o menos así: existe una práctica preinstitucionalizada que tiene un valor interno. Cuántas personas reconozcan ese valor como un bien es relevante solo en cuanto permita la institucionalización de la práctica. Cómo se logra esa institucionalización si por fuerza o apoyo o alguna combinación de esos u otros factores, es algo que no me interesa ni tengo las capacidades para desarrollar. Sin embargo, me parece que el punto del análisis desarrollado por MacIntyre se sostiene: que una práctica se institucionaliza y el problema está en que esa institucionalización, que busca mantener el bien de la práctica, es siempre imperfecta. ${ }^{8}$

Ahora bien, no estoy seguro si entiendo la idea sobre la existencia de "males" internos. Siguiendo a MacIntyre me cuesta ver la lógica de una práctica en la que existan "males" internos. ¿Cuál sería el sentido de tener una práctica entonces? ¿Qué necesidad humana puede satisfacerse con un "mal" interno de una práctica? Puede sonar a petición de principio, pero es de toda lógica que no parecen haber buenas razones para querer institucionalizar una práctica fundada en males.

En cuanto a la pedagogía que supone la realización repetitiva de las reglas de la institución (el ejemplo del ajedrez que no convence a Bouvier), quizá el escepticismo va más allá de lo que cree el propio Bouvier, ya que la forma en que cuestiona este tipo de explicación negaría una tarea como la de reconciliación que se propone Hegel y que puede inspirar la filosofía política, esto es, explicar las razones por las que ciertas instituciones no son irracionales a pesar de no ser equivalentes a nuestros deseos. El elemento deficitario del paradigma clásico puede verse en esta discusión: no es una explicación teórica adecuada porque asume que la práctica de los impuestos se desarrolla sobre una realidad institucional: la de la propiedad privada. Por

8 Aquí me remito a la respuesta que doy a Eleonora Lozano sobre la necesidad de adhesión interna a las reglas de la institución. 
eso las apelaciones puramente individuales para justiciar la "afectación" de la propiedad privada mediante la redistribución. Este fundamento, como he dicho más arriba acarrea problemas graves para la aplicación de los impuestos: la institución pierde todo elemento solidario para depender exclusivamente de la voluntad de quién quiera pagar, lo que se refleja en la forma en que el paradigma clásico entiende la elusión tributaria.

Ahora queda por discutir el elemento normativo de RDI, lo que a Bouvier parecen "bases insuficientes".

\subsection{Reconocimiento y explicación}

Tiene razón Bouvier en que puede haber otras razones normativas, distintas a las que uso en RDI, para criticar el paradigma clásico. También tiene razón Bouvier al adelantar mi respuesta a su comentario sobre la necesidad de mostrar que los impuestos pueden formar parte de lo que merece buscarse. En este sentido, ¿qué quiere decir que los impuestos merecen buscarse? ¿Se refiere a formas de obtener recursos públicos? ¿Qué son los impuestos?

Bouvier acepta que una refutación de una "explicación teórica" que los impuestos se explican mejor de una forma no instrumental, vale decir, en los términos que he venido desarrollando en esta respuesta, que una explicación funcional de los impuestos no implica que los impuestos se puedan explicar por esa función. Esto es equivalente a sostener como hacer Bouvier, que pueden haber impuestos que no financian el gasto del Estado y que hay gastos del Estado que podrían financiarse sin impuestos. Tiene razón Bouvier en que no menciono esas alternativas, pero tiene razón también cuando asume que estoy haciendo referencia implícita a las formas tradicionales en que se discute el financiamiento del Estado más allá de los impuestos (propiedad de empresas, deuda, etc, más allá de las consecuencias o efectos económicos no deseados que estas alternativas pudieran tener).

Lo que no puedo dejar de recalcar es que, a mi juicio, lo que merece buscarse no son los impuestos como mecanismos de recaudación, mi argumento no es un argumento normativo solo para dar cuenta de eso (de lo contrario caería en el paradigma clásico). Lo que merece buscarse son las razones que explican que los impuestos se recauden de la manera que se 
recaudan, la relación entre propiedad privada e impuestos como conceptos institucionales, que las obligaciones tributarias tengan su fuente en la ley, que la elusión tributaria sea una conducta que deja sin efecto las obligaciones tributarias en la forma prevista por el legislador. Esto es, los elementos del derecho tributario que van más allá de la obtención de recursos (porque esto último se podría hacer con otros medios).

Estoy de acuerdo con Bouvier en que el paradigma clásico como explicación teórica y en su versión de justificación adolece de problemas de extensión y contradicciones pragmáticas, respectivamente. No puedo ahondar ahora en esa linea, pero espero desarrollar esos argumentos en paralelo y en apoyo de RDI.

\subsection{Elusión y desprecio}

No estoy seguro de que los ejemplos de Bouvier correspondan a casos de elusión. Tres análisis previos a la calificación de elusión creo son necesarios: (i) la regulación positiva del derecho tributario del sistema jurídico que se trate; (ii) la regulación positiva contra la elusión (si existen reglas especiales, reglas o principios generales antielusión); (iii) la aplicación de la regulación positiva contra la elusión a un caso particular. Todo esto además asumiendo que la teoría del hecho gravado se construye sobre el paradigma clásico.

Así, el caso del matrimonio para pagar menos impuestos no es necesariamente uno de elusión. Primero será necesario analizar si el derecho tributario establece un tratamiento privilegiado a los casados. Luego, si existen reglas especiales o generales, o principios generales antielusión. En caso que existan, podría ser que la regulación establezca condiciones de interpretación sustantivas sobre las instituciones del derecho privado que se trate (por ejemplo, qué constituye un verdadero matrimonio para efectos del beneficio tributario).

Lo mismo se puede aplicar respecto del ejemplo consistente en "declarar el auto nuevísimo como perteneciente a la empresa o sociedad para luego poder descargarlos como inversión en la empresa evitando la carga por adquisición de bienes personales". Primero, asumiendo con Bouvier que existe una regla que impide usar los autos de la empresa para beneficio 
personal de los dueños, estaríamos ante un caso que un acto legal, deja sin efecto el derecho tributario. En otras palabras, podemos asumir para efectos del ejemplo que la base imponible se ve erosionada en la definición del hecho gravado por esta acción. En caso de que exista regulación positiva de la elusión, será necesario aplicarla al caso particular.

En ninguno de estos casos necesitamos afirmar que la elusión es una pura cuestión moral o normativa, como parece creer Bouvier que haría RDI cuando afirma que son "estrategias cuya maldad hay que probar más allá de las antipatías que nos generen". En eso también estamos de acuerdo.

RDI, sin embargo, permitiría mostrar que se trata de casos de elusión sin necesitar la existencia de regulación positiva de la elusión. Esa es la diferencia con el paradigma clásico. ¿Por qué? Porque la definición del derecho tributario debería atender a sus fines para la aplicación y justificación de las normas que establecen hechos gravados a casos particulares. Se necesitaría entonces analizar si en el caso del matrimonio o en el de la compra del auto a través de una empresa, se aprovecha de un beneficio para fines no previstos por el legislador o se deja sin efecto el derecho tributario ahí donde su buscó aplicarlo. Pero todo eso dependerá de la situación de hecho.

Para RDI es posible mantener la diferencia entre elusión y evasión, pero redefiniéndola. Recuerden que el paradigma clásico considera que se trata de conductas legales conforme al ordenamiento jurídico general, que dejan sin efecto el derecho tributario, por lo que es necesario demostrar que subjetivamente hubo intención de eludir; y conductas abiertamente ilegales desde el punto de vista del ordenamiento jurídico general y del derecho tributario. Para RDI, en cambio, la diferencia está en que las conductas elusivas no se considerarían legales para el derecho tributario sin necesidad de ser calificadas como elusión; la aplicación sustantiva del derecho tributario sería parte de las categorías propias de esta área del derecho y operarían en la determinación de las obligaciones tributarias.

Planteada la forma en que RDI consideraría la elusión, me atrevo a formular dos posibles respuestas a las últimas objeciones de Bouvier. En primer lugar, a juicio de Bouvier podría existir el riesgo que una autoridad judicial indique que se ha infringido una ley cuando, bajo la interpretación clásica del derecho tributario, la conducta de un contribuyente no es "captada" por una norma. El riesgo estaría, a juicio de Bouvier en que se podría 
recurrir a la solidaridad como razón subyacente para ampliar el alcance de los términos de las normas. Creo que aquí va muy rápido Bouvier. De hecho, una de las razones que doy para descartar una comprensión del derecho tributario construida en base a principios, como sugiere por ejemplo Judith Freedman, es precisamente el tipo de problemas que identifica Bouvier. Lo que RDI plantea es la necesidad de repensar la forma en que el derecho tributario da forma a las obligaciones particulares, dogmáticamente: cómo se explica la generación de una obligación legal en un caso determinado, conforme a un fundamento de la obligación basado en RDI. No se trata, entonces, de apelar a la pura sustancia solidaria para fundamentar obligaciones legales. ${ }^{9}$

Considerando lo anterior es más fácil responder la segunda y última objeción: no habría sorpresa que genere desprecio en la determinación de las obligaciones tributarias bajo RDI. La idea es desarrollar una forma de determinación de las obligaciones tributarias en cada caso particular, pero con una pequeña modificación a lo señalado por Bouvier. Sea cual fuere la forma jurídica que permita encarnar las ideas de RDI, en ningún caso habría sorpresa para quien sabe de antemano que el solo hecho de tener propiedad privada podría generar una obligación tributaria. Me imagino que Bouvier no quiere decir en esta última objeción que no despreciar a un sujeto es permitirle "prepararse o decidir con todos los hechos, normas y razones sobre la mesa" cuando decide eludir. Lo que quiere decir Bouvier es que esa persona puede determinar en qué caso quiere estar fuera de la ley a su propio riesgo. RDI le da razones para considerar que cada vez que estructura sus negocios con la finalidad de eludir sus obligaciones tributarias está en una posición de incumplimiento legal.

\section{Bibliografía}

Brooks, T. (2012). Reciprocity as mutual recognition. The Good Society, 21(1), 21-35. 
Cohen, G.A. (2000). Karl Marx's Theory of History a Defence. Oxford: Oxford University Press.

Gonçalves, J. A. L. (2002). Imposto sobre a renda: pressupostos constitucionais. São Paulo: Malheiros.

Habermas, J (1990). Justice and Solidarity: On the discussion concerning Stage 6. En S. Weber Nicholsen (eds.), The Moral Domain: Essays in the Ongoing Discussion between Philosophy and the Social Sciences. Cambridge: MIT Press.

Hardimon, M. (1992). The project of reconciliation: Hegel's Social Philosophy. Philosophy \& Public Affairs, 21(2), 165-195.

Hardimon, M. (1994). Hegel's Social Philosophy. The Project of Reconciliation. Cambridge: Cambridge University Press.

Hart, H. L. A. (1994). The Concept of Law. Oxford-New York: Clarendon Press Oxford University Press.

Moon, D. (1977). Understanding and Explanation in Social Science: On Runciman's critique of Weber. Political Theory, 5(2), 183-198.

OECD (2019). Tax Morale: What Drives People and Businesses to Pay Tax? OECD Publishing, Paris, https://doi.org/10.1787/f3d8ea10-en.

Rehg, W. (1997). Insight \& Solidarity. The Discourse Ethics of Jürgen Habermas. Berkeley: University of California Press.

Ruben, D (1990). Singular explanation and the social Sciences. Royal Institute of Philosophy Supplement, 27, 95-117.

Saffie, F. (2012). El impuesto a las herencias como una institución de justicia. Estudios Públicos, (126), 123-161.

Skorupski, J. (1990). Explanation in the social sciences: Explanation and understanding in social science. Royal Institute of Philosophy Supplement, 27, 119-134.

Taylor, D. (1970). Explanation \& Meaning. An Introduction to Philosophy. Cambridge: Cambridge University Press. 